\title{
Transmucosal Delivery of Nicotine in Combination with Tincture of Benzoin Inhibits Apoptosis
}

\author{
Alex Battaglia $^{1,3}$ (ID $\cdot$ Thanh Nguyen $^{2}$
}

Published online: 20 October 2017

(C) The Author(s) 2017. This article is an open access publication

\begin{abstract}
Background and Objective The aim of this study was to test the hypothesis that tincture of benzoin (TOB) facilitates immediate transmucosal nicotine absorption while simultaneously promoting a safe and sustained delivery of the nicotine.

Methods In combination with TOB, nicotine toxicity and diffusion across human mucosal cells were measured using a 3-D human mucosal tissue model.

Results Nicotine was delivered 2.1 times more quickly in combination with TOB than in combination with saline $(p<0.05)$. Despite the increased diffusion, nicotine in combination with TOB significantly increased mucosal cell survival $(p<0.05)$ by reducing the release of mitochondrial cytochrome $c$ into the cytoplasm when compared with nicotine without TOB. The average percentage distribution of cytochrome $c$ in the cytosolic fraction over time of nicotine $+79 \%$ ethyl alcohol $($ ETOH) versus nicotine plus TOB (79\% ETOH) was significantly different over 120 min $(60.0 \pm 29.9 \%$ cytosol, $16.1 \pm 9.4 \%$ cytosol, $p=0.03$ ). Related to the reduction of cytochrome $c$ release into the cytoplasm, TOB suppressed caspase-3 and -9 activity, thereby preventing intrinsic apoptosis and providing cytoprotection of the mucosal cells
\end{abstract}

Alex Battaglia

alexbattaglia@me.com

1 Department of Surgery, University of California, San Diego, Health Sciences, 9500 Gilman Drive, La Jolla, CA 92093, USA

2 Advantar Labs, 5451 Oberlin Dr. Suite 100, San Diego, CA 92121, USA

36454 Autumn Gold Way, San Diego, CA 92130, USA
$(\mathrm{ETOH}+$ nicotine $\quad$ vs $\quad \mathrm{ETOH}+$ nicotine + TOB $:$ $p=0.008$ for caspase $3, p<0.001$ for caspase 9).

Conclusion Two hours of TOB (17-24\% benzoin, $79 \%$ ETOH) plus nicotine promotes diffusion of nicotine across human mucosal cells and simultaneously prevents human mucosal cell toxicity by inhibiting cytochrome $c$ release into the cytosol, thereby preventing caspase 3 and 9 activity and subsequent intrinsic apoptosis.

\section{Key Point}

Two hours of tincture of benzoin (TOB) (17-24\% benzoin, $79 \%$ ethyl alcohol) plus nicotine promotes diffusion of nicotine across human mucosal cells when compared with a commercial nasal nicotine plus saline formulation, prevents human mucosal cell toxicity by inhibiting cytochrome $c$ release into the cytosol, and this in turn prevents caspase 3 and 9 activity and subsequent intrinsic apoptosis.

\section{Introduction}

Cigarette smoking accounted for at least $48 \%$ of all cancerrelated deaths between 2005 and 2009 [1]. Nicotine Replacement Therapy (NRT) products for smoking cessation include nicotine-containing gums, patches, lozenges, sublingual tablets, inhalers, and mouth sprays. The most widely used NRT products are nicotine gums, and the market for these was valued at US\$995.5 million in 2012. Despite its large market share, nicotine gums are clinically limited by the slow rate of nicotine transbuccal absorption 
and also by their notable gastrointestinal side effects. The craving-relief effect of nicotine gum begins at the 15- to 20 -min point, and as a result the quit rate for smokers using nicotine gum is reported to be as low as $3-8 \%$ within 6 months [2,3]. The speed of onset of an NRT product is critical, with data to suggest that if acute cravings are not satisfied within $10 \mathrm{~min}$, the likelihood of relapse is high [4]. Nicotine sprays and inhalers were developed to address the need for rapid onset but are beset by short-term craving relief and side effects that diminish patient satisfaction. The recent success of e-cigarettes since 2007 in the US is related to their speed of onset, minimal associated side effects, and also a perceived but undocumented safety profile relative to cigarettes.

It is difficult to study the safety profile of e-cigarettes given very few people have used e-cigarettes for an extended period of time [1]. Toxicants from e-cigarette inhalation include carcinogens such as formaldehyde, acetaldehyde, $N$-nitrosonornicotine $(\mathrm{NNN})$, and 4( $N$-nitrosomethyamino)-1-(3-pyridyl)-1-butanone (NNK), and evidence exists that passive second-hand vaping of toxicants can occur [5-8]. In addition, e-cigarettes have been shown to reduce lung function, are not associated with long-term smoking cessation, and are used widely by underage consumers [1, 9-12].

The ideal NRT product, therefore, should quickly $(<10 \mathrm{~min})$ reduce powerful nicotine cravings, have a prolonged effect to reduce continual product use, minimize associated nicotine side effects, eliminate inhalation and second-hand vapor/smoke, and simultaneously should not be attractive to teens. To this end, nicotine was combined with tincture of benzoin (TOB) (nicotine $1 \mathrm{mg} / \mathrm{TOB}$ $50 \mu \mathrm{L}$ ). TOB is an oral mucosal protectant that is FDA and American Dental Association approved for use in the mouth, is on the GRAS list (generally recognized as safe) as a food additive, and is a well accepted treatment for intraoral stomatitis. TOB contains $17-24 \%$ Sumatran benzoin resin solubilized in $79 \%$ ethanol. After it is applied to the mucosa, the benzoin resin forms a bioprotective film that adheres to the oral mucosa for up to $2 \mathrm{~h}$.

In combination with nicotine, the TOB is hypothesized not only to facilitate immediate nicotine absorption because of its alcohol content, but also to promote a safe and sustained delivery of the nicotine. The sustained release is thought to occur because the benzoin biofilm that adheres to the mucosa is impregnated with nicotine, and the nicotine can then be released by this biofilm steadily over time. These hypotheses are tested with an in vitro transcellular diffusion model utilizing cultured human mucosal cells.

\section{Methods}

\subsection{Nicotine Diffusion Across Human Mucosal Cells}

Twenty-four-well EpiOral human mucosal cells in a 3-D mucosal model (http://www.mattek.com) were transferred from agarose to assay medium and incubated at $37 \pm 1{ }^{\circ} \mathrm{C}$, $5 \pm 1 \% \mathrm{CO}_{2}, 95 \%$ relative humidity (RH) for $60 \pm 5 \mathrm{~min}$. Tissues were transferred to fresh medium and incubated at $37 \pm 1{ }^{\circ} \mathrm{C}, 5 \pm 1 \% \mathrm{CO}_{2}, 95 \% \mathrm{RH}$ overnight $(18 \pm 3 \mathrm{~h})$. Three tissues each were treated for $2 \mathrm{~h}$ at $37 \pm 1{ }^{\circ} \mathrm{C}$, $5 \pm 1 \% \mathrm{CO}_{2}, 95 \% \mathrm{RH}$ with either $50 \mu \mathrm{L}$ of freshly prepared assay medium without active ingredient (negative control, $\mathrm{pH}$ 8.5), $50 \mu \mathrm{L}$ commercially available nicotine nasal spray $(1 \mathrm{mg} / \mathrm{mL}$ ) (positive control, $\mathrm{pH} 8.5$ ), $50 \mu \mathrm{L}$ nicotine in vehicle without TOB $(1 \mathrm{mg} / \mathrm{mL}$ nicotine, $2 \%$ peppermint, $79 \%$ ethanol, $\mathrm{pH} 8.5), 50 \mu \mathrm{L}$ nicotine in TOB ( $2 \%$ peppermint, $\mathrm{pH} 8.5$ ). The concentration of nicotine was measured with high-performance liquid chromatography (HPLC) to verify the starting concentration of each test article. Fifty microliters of medium was collected from the receptor well at 10, 20, 30, 45, 60, and $120 \mathrm{~min}$. Studies were conducted over $120 \mathrm{~min}$ to mimic the maximum residence time of nicotine plus TOB in the oral cavity. Fifty microliters of fresh neat medium was then placed in the receptor well to replace the lost medium and to maintain contact of receptor medium with the tissue. HPLC-UV was performed on each sample. The sample was diluted for HPLC with methanol. Chromatography was performed on an Xbridge column using a gradient of acetonitrile and methanol. Nicotine was monitored at $260 \mathrm{~nm}$.

\subsection{Tissue Viability}

To assess the tissue viability following exposure to the various samples above, the tissues were rinsed with PBS and loaded with 3-(4,5-dimethylthiazole-2-yl)-2,5-diphenyl tetrazolium bromide (MTT; mattek.com). Tissues were placed into a 24-well plate containing $300 \mu \mathrm{L}$ of MTT $(1 \mathrm{mg} / \mathrm{mL})$ and incubated for $3 \mathrm{~h}$ at $37{ }^{\circ} \mathrm{C}, 5 \% \mathrm{CO}_{2}$. After incubation with MTT, the culture inserts were transferred into 24-well plates containing $2.0 \mathrm{~mL}$ of extractant (mattek.com); extraction of the MTT from the tissues was allowed to continue overnight (in the dark, at room temperature). The resulting extract was quantified by measuring the optical density (OD) at $570 \mathrm{~nm}$ using a UV spectrophotometer. The tissue viability was determined by normalizing to the OD for untreated tissues using the following equation: $\%$ viability $=\mathrm{OD}$ (treated tissue)/OD (untreated tissue) $\times 100$. 


\subsection{Caspase Analysis}

The Caspase-Glo ${ }^{\circledR}$ assays utilize a luminogenic caspase-9 tetrapeptide substrate (Z-LEHD-aminoluciferin) or a caspase-3/7 substrate (Z-DEVD-aminoluciferin), and a stable luciferase in buffers optimized for specific caspase activity, cell lysis, and luciferase activity. In the absence of active caspase, the caspase substrates do not act as substrates for luciferase and thus produce no light. Upon cleavage of the substrates by the respective caspase, aminoluciferin is liberated and can contribute to the generation of a luminescent signal directly proportional to the amount of caspase activity present in the sample. 24-well EpiOral human mucosal cells in a 3-D mucosal model (http://www.mattek.com) were transferred from agarose to assay medium and incubated at $37 \pm 1{ }^{\circ} \mathrm{C}, 5 \pm 1 \% \mathrm{CO}_{2}$, $95 \% \mathrm{RH}$ for $60 \pm 5 \mathrm{~min}$. Tissues were transferred to fresh medium and incubated at $37 \pm 1{ }^{\circ} \mathrm{C}, 5 \pm 1 \% \mathrm{CO}_{2}, 95 \%$ RH overnight ( $18 \pm 3 \mathrm{~h})$. Six tissues each were treated for $2 \mathrm{~h}$ at $37 \pm 1{ }^{\circ} \mathrm{C}, 5 \pm 1 \% \mathrm{CO}_{2}, 95 \% \mathrm{RH}$ with either $50 \mu \mathrm{L}$ of assay medium without active ingredient (negative control), $50 \mu \mathrm{L}$ nicotine in vehicle without TOB $(1 \mathrm{mg} / \mathrm{mL}$ nicotine, $2 \%$ peppermint, $79 \%$ ethanol, $\mathrm{pH} 8.5$ ) (positive control), $50 \mu \mathrm{L}$ nicotine in vehicle without TOB $(1 \mathrm{mg} / \mathrm{mL}$ nicotine, $2 \%$ peppermint, $79 \%$ ethanol, $\mathrm{pH} 8.5)+50 \mu \mathrm{M}$ of the caspase inhibitor Z-VAD-FMK, or $50 \mu \mathrm{L}$ nicotine in TOB $(1 \mathrm{mg} / \mathrm{mL}$ nicotine, $2 \%$ peppermint, $\mathrm{pH} 8.5)$. The Caspase-Glo 3/7 and 9 reagents were then prepared and allowed to equilibrate to RT and mixed well. 3/7 Reagent or Caspase-Glo 9 reagent was added to three wells from each treatment group and then placed on a plate shaker at $300-500 \mathrm{rpm}$ for $30 \mathrm{~s}$. Incubation was performed at room temperature for $1 \mathrm{~h}$. Luminescence of each sample was measured in a plate-reading luminometer. A blank reaction using the Caspase-Glo 3/7 reagent or the Caspase-Glo 9 reagent, the vehicle and cell culture medium without cells, was used to measure background luminescence associated with the cell culture system, and this value was subtracted from experimental values.

\subsection{Cytochrome $c$ Quantification}

\subsubsection{Cell Fractionation (ab109718)}

24-well EpiOral human mucosal cells (http://www.mattek. com) were transferred from agarose to assay medium and incubated at $37 \pm 1{ }^{\circ} \mathrm{C}, 5 \pm 1 \% \quad \mathrm{CO}_{2}, 95 \% \mathrm{RH}$ for $60 \pm 5 \mathrm{~min}$. Tissues were transferred to fresh medium and incubated at $37 \pm 1{ }^{\circ} \mathrm{C}, 5 \pm 1 \% \quad \mathrm{CO}_{2}, 95 \% \mathrm{RH}$ overnight $(18 \pm 3 \mathrm{~h})$. Eight tissues each were treated for $2 \mathrm{~h}$ at $37 \pm 1{ }^{\circ} \mathrm{C}, 5 \pm 1 \% \mathrm{CO}_{2}, 95 \% \mathrm{RH}$ with either $50 \mu \mathrm{L}$ of assay medium without active ingredient (negative control), $50 \mu \mathrm{L}$ nicotine in vehicle without TOB
$(1 \mathrm{mg} / \mathrm{mL}$ nicotine, $2 \%$ peppermint, $79 \%$ ethanol, $\mathrm{pH} 8.5), 50 \mu \mathrm{L}$ nicotine in TOB $(2 \%$ peppermint, $\mathrm{pH}$ 8.5). The human oral mucosal cells from each group were then washed and cytosolic extraction performed using $50 \mu \mathrm{L}$ of extraction buffer per well for 7 min at RT. Centrifugation was performed for $3 \mathrm{~min}$ at $300 \mathrm{~g}$ in $1.5 \mathrm{~mL}$ eppendorf tubes. The supernatant containing the cytosolic fraction was then removed and saved on ice, and then mitochondrial extraction was performed. Mitochondrial extraction buffer $50 \mu \mathrm{L}$ was added to the resulting pellet for $10 \mathrm{~min}$ at RT with gentle agitation, and then centrifugation was performed at $300 \mathrm{~g}$ for $3 \mathrm{~min}$ at RT. The supernatant containing the mitochondrial proteins was removed and saved on ice in a fresh labeled eppendorf tube. Nuclear extraction buffer $50 \mu \mathrm{L}$ was then added for $10 \mathrm{~min}$ at RT with gentle agitation, and centrifugation repeated for $3 \mathrm{~min}$ at $300 \mathrm{~g}$ RT. The supernatant containing the nuclear extraction was removed and saved on ice in a fresh labeled eppendorf tube.

\subsubsection{Cytochrome c Protein Quantity Microplate Assay (ab110172)}

Each of the mitochondrial, cytosolic or nuclear extractions was loaded into individual wells on microplates precoated with cytochrome $c$ capture antibodies. A buffer control was used as a null or background reference. The microplate was incubated for $3 \mathrm{~h}$ at room temperature. A buffer solution was prepared by adding $15 \mathrm{~mL} 20 \times$ wash buffer (tube 3) to $285 \mathrm{~mL}$ deionized $\mathrm{H}_{2} \mathrm{O}$ (wash solution). Wash solution $45 \mathrm{~mL}$ was then placed into a clean bottle and $5 \mathrm{~mL}$ of $10 \times$ blocking solution was added (incubation solution). The wells were emptied quickly by turning the plate upside down and shaking out any remaining liquid. Wash solution $300 \mu \mathrm{L}$ was added to each well used. $20 \times$ detector antibody $1 \mathrm{~mL}$ was added to $20 \mathrm{~mL}$ of incubation solution and $200 \mu \mathrm{L}$ of this detector solution was added to each well. The plate was incubated for $1 \mathrm{~h}$ at room temperature. The wells of the plate were emptied and $300 \mu \mathrm{L}$ of wash solution added to each well used. $20 \times$ horseradish peroxidase (HRP) label $1 \mathrm{~mL}$ was added to $20 \mathrm{~mL}$ of incubation solution, the wells emptied again, and then $200 \mu \mathrm{L}$ of this label solution was added to each well. The plate was incubated for $1 \mathrm{~h}$ at room temperature. The wells were emptied again and $300 \mu \mathrm{L}$ of wash solution added to each well. This wash step was repeated four more times and the wells then emptied. Development solution $200 \mu \mathrm{L}$ was added to each well used. The absorbance of each well was measured at $600 \mathrm{~nm}$ at room temperature using a spectrophotometer. A measurement was made at 15, 30, 60, and 120 min. A paired, two-tailed $t$ test was performed comparing cytosolic fractions. 


\section{Results}

\subsection{Nicotine Diffusion Across Human Mucosal Cells}

HPLC analysis of the concentration of nicotine across human mucosal cells indicates that in combination with saline, diffusion occurs much more slowly than in the presence of $79 \%$ concentrations of ethanol. Over time, diffusion of nicotine was accelerated by TOB in comparison with saline but reduced in comparison with ethanol without benzoin (Fig. 1).

\subsection{Tissue Viability}

UV spectrophotometer analysis revealed that $13 \%$ of the human mucosal cells became non-viable (87\% survival rate) after $2 \mathrm{~h}$ of exposure to $70 \%$ ethanol, while TOB with the same concentration of ethanol did not reduce cell viability (survival rate 100\%). With the addition of nicotine at $1 \mathrm{mg} / \mathrm{mL}$ to $70 \%$ ethanol, tissue viability dropped to $49 \%$ after $2 \mathrm{~h}$, while the addition of TOB with the same nicotine concentration led to a $94 \%$ cell survival rate $(p<0.05$, ANOVA). When added to saline alone at $\mathrm{pH} 8.5$, nicotine at $1 \mathrm{mg} / \mathrm{mL}$ led to a $98 \%$ cell survival rate (Fig. 2).

\subsection{Caspase Analysis}

The cause of human mucosal cell toxicity was investigated by measuring caspase 3 and caspase 9 activity after

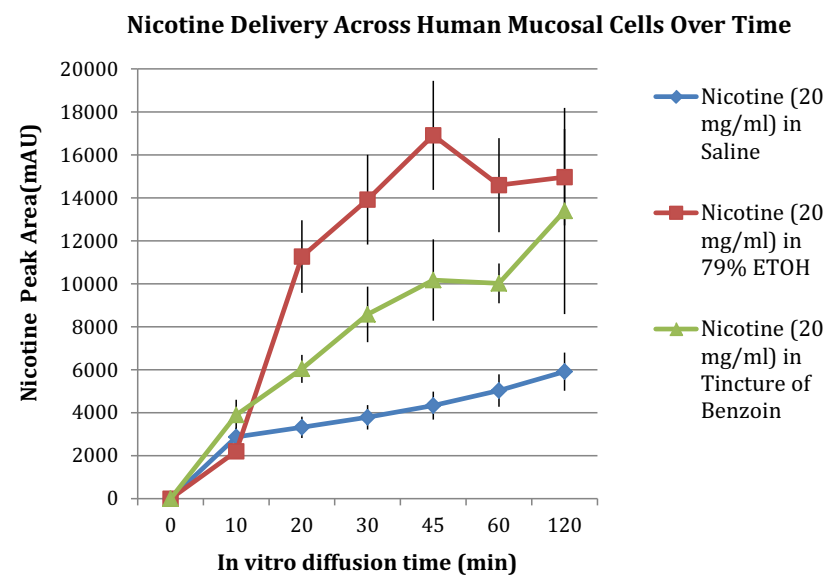

Fig. 1 Ethanol and tincture of benzoin (TOB) accelerate the delivery of nicotine across human mucosal cells in comparison with saline, whereas TOB (benzoin gum in $79 \%$ ethanol) slows the delivery of nicotine in comparison with $79 \%$ ethanol alone. Over the first $10 \mathrm{~min}$, diffusion was indistinguishable, but by the 20-min point and after, nicotine in the presence of ethanol had an average diffusion rate (mAU/min) 2.1 times that of nicotine plus saline. In contrast, the diffusion rate of nicotine in the presence of TOB was on average 2.1 times that of nicotine in the presence of saline $(p<0.05$, ANOVA). ANOVA analysis of variance, ETOH ethyl alcohol
Tincture of Benzoin Cytoprotection of Human Mucosal Cells

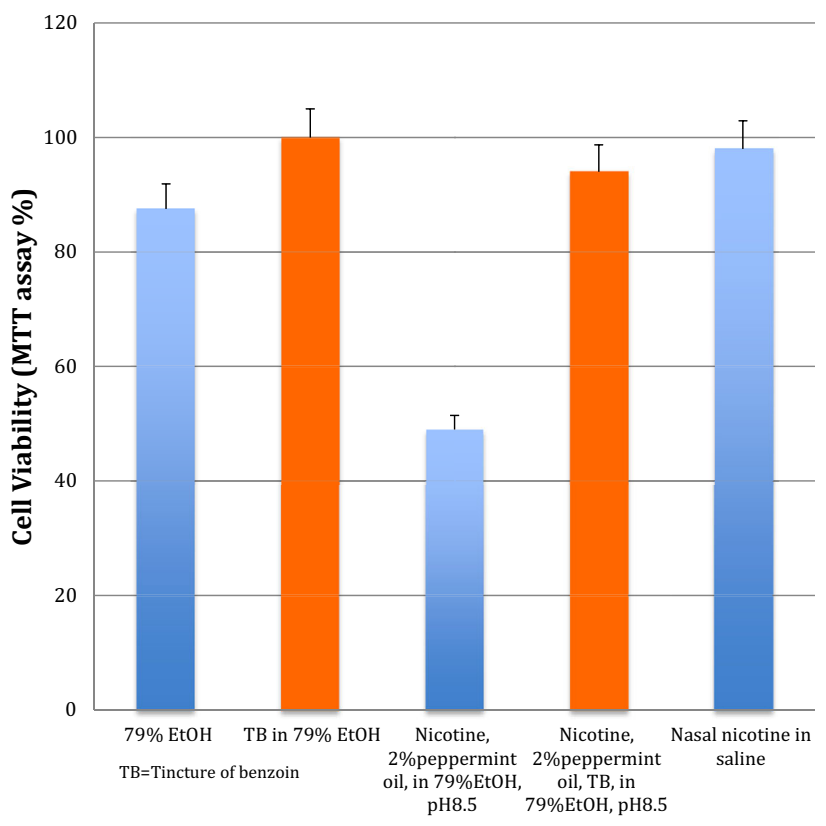

Fig. 2 Tincture of benzoin (TOB) provides statistically significant cytoprotection for human mucosal cells from toxicity induced by ethanol + nicotine at $1 \mathrm{mg} / \mathrm{mL}$ after $2 \mathrm{~h}(p<0.05$, ANOVA). ANOVA analysis of variance, ETOH ethyl alcohol, MTT 3-(4,5dimethylthiazole-2-yl)-2,5-diphenyl tetrazolium bromide

exposure to nicotine formulations $(1 \mathrm{mg} / \mathrm{mL})$ with and without TOB (Fig. 3). The average luminescence readings correlate with caspase activity and are shown in Table 1 . The luminescence readings indicate that $\mathrm{ETOH}+$ nicotine activates both caspase 3 and caspase 9 , and that this activation is inhibited both by Z-VAD-FMK and TOB. The difference between the means of the $\mathrm{ETOH}+$ nicotine luminescent readings, the $\mathrm{ETOH}+$ nicotine $+\mathrm{Z}-\mathrm{VAD}$ FMK, and the ETOH + nicotine + TOB readings is statistically significant $(\mathrm{ETOH}+$ nicotine vs $\mathrm{ETOH}+$ nicotine + TOB: $p=0.008$ for caspase $3, p<0.001$ for caspase 9). There is no significant difference between the $\mathrm{ETOH}+$ nicotine $+\mathrm{Z}$-VAD-FMK readings and the $\mathrm{ETOH}+$ nicotine + TOB readings.

\subsection{Cytochrome $c$ Quantification}

To further investigate the cause of Caspase 3 and 9 activation and its relation to human mucosal cell toxicity, human mucosal cells were fractioned into cytosolic, mitochondrial and nuclear components after treatment with nicotine $(1 \mathrm{mg} / \mathrm{mL}) \pm$ TOB for $2 \mathrm{~h}$. Cytochrome $c$, a wellknown activator of the intrinsic pathway of apoptosis via mitochondrial release into the cytosol and secondary activation of caspase 3 and 9, was then quantified in each 
Caspase 3 and 9 Inhibition in Human Buccal Cells after Treatment with Tincture of Benzoin + Nicotine

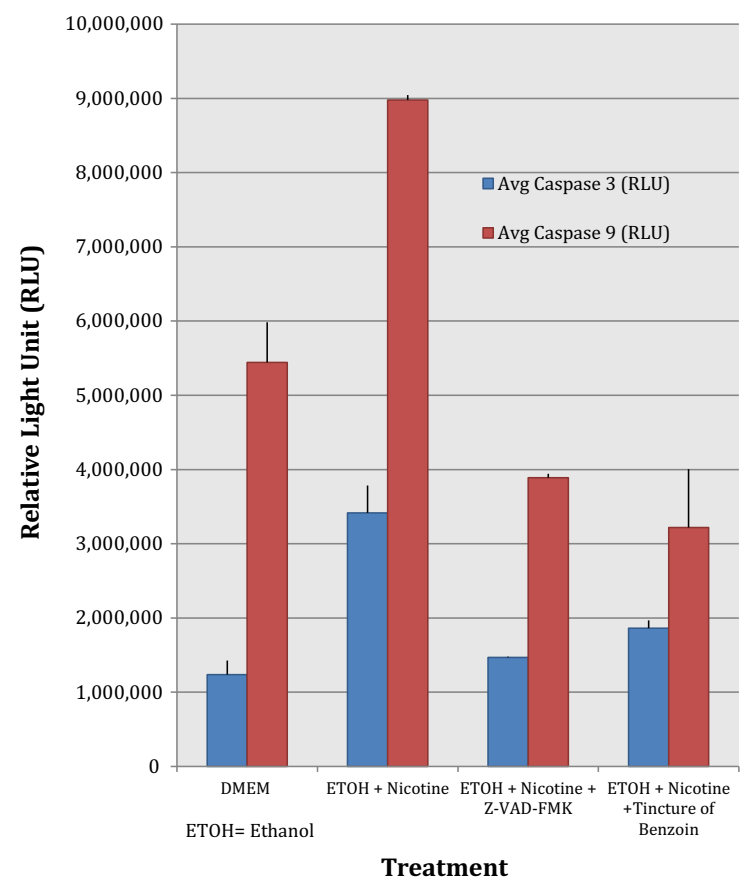

Fig. $3 \mathrm{ETOH}+$ nicotine at $1 \mathrm{mg} / \mathrm{mL}$ triggers both caspase 3 and caspase 9 activity after $2 \mathrm{~h}$, while TOB significantly reduces caspase 3 and 9 activation $(p<0.05$, ANOVA). ANOVA analysis of variance, DMEM Dulbecco's Modified Eagle Medium, ETOH ethyl alcohol

fraction using a cytochrome capture antibody that is secondarily labeled with an HRP system. The average percentage distribution of cytochrome $c$ in the cytosolic fraction over time of nicotine $+79 \%$ ETOH vs nicotine + TOB $(79 \%$ ETOH) was significantly different over $120 \mathrm{~min}(60.0 \pm 29.9 \%$ cytosol, $16.1 \pm 9.4 \%$ cytosol, $p=0.03)$. The Dulbecco's Modified Eagle Medium (DMEM) control average was $33.9 \pm 7.7 \%$ cytosol. The results indicate that ethanol + nicotine causes a shift of cytochrome $c$ into the cytoplasm with minimal retention in the mitochondria. When nicotine is combined with TOB, however, minimal release of cytochrome $c$ into the cytoplasm occurs until the 2 -h point. The reduced release of cytochrome $c$ into the cytosol provides a possible explanation of the cytoprotection offered by TOB from nicotine + ETOH toxicity.

\section{Discussion}

\subsection{In Vitro Effects of Ethanol + Nicotine on Human Mucosal Cells and the Cytoprotection Conferred by TOB}

The transcellular diffusion results obtained from this study demonstrate that nicotine $+79 \%$ ethanol administration causes an increased diffusion of nicotine across human mucosal cells compared with nicotine in saline alone. These results are not surprising given the fact that ethanol as a penetration enhancer is well characterized [13-29]. Generally, ethanol is thought to increase the permeability of skin or mucosa by disrupting the lipid bilayer of the cell membrane. The mechanism of ethanol as a skin permeation enhancer is described to have a 'pull' or 'drag' effect, wherein the permeation of ethanol subsequently facilitates that of the solute (in the sense of a simple co-permeation). Bommanan et al. found that ethanol removes measurable quantities of the lipid barrier material from human skin in vivo [30]. Lipid extraction occurs and may lower the skin barrier function and render the membrane more permeable, which is the most likely explanation for the effect of ethanol as a skin penetration enhancer. Kai et al. and van der Merwe et al. published confirmatory results [31, 32]. Goates and Knutson additionally noted that the enhanced permeation caused by ethanol may be caused not only by extraction of lipids but also of proteins from human skin [33]. Nicotine in TOB (79\% ethanol) showed an increase in nicotine diffusion compared with nicotine in saline but reduced compared with nicotine in $79 \%$ ethanol alone. The reduction in nicotine transport compared with ethanol alone may simply be related to mechanical stabilization of the lipid bilayer of the cell membrane by the benzoin resin, though further investigation is warranted.

Table 1 Average luminescence of human mucosal cells as an indication of caspase 3 and caspase 9 activity after 2-h exposure to nicotine formulations with and without TOB and also the caspase inhibitor Z-VAD-FMK

\begin{tabular}{llr}
\hline Test article & Avg caspase 3 (RLU) & Avg caspase 9 (RLU) \\
\hline DMEM (negative control) & $1,236,385 \pm 10,757$ & $5,444,720 \pm 50,121$ \\
ETOH + nicotine (positive control) & $3,416,346 \pm 191,094$ & $8,979,126 \pm 540,531$ \\
ETOH + nicotine + Z-VAD-FMK & $1,467,379 \pm 368,190$ & $3,891,464 \pm 64,085$ \\
ETOH + nicotine + TOB & $1,863,701 \pm 102,121$ & $3,218,476 \pm 788,654$
\end{tabular}

The difference between the means of the (ETOH + nicotine vs ETOH + nicotine + TOB) is statistically significant for both caspase 3 and 9 $(p<0.05$, ANOVA)

DMEM Dulbecco's Modified Eagle Medium, ETOH ethyl alcohol, RLU Relative Light Units, TOB tincture of benzoin 
The increased diffusion of nicotine in combination with ethanol alone correlates with a dramatic increase in human mucosal cell toxicity compared with nicotine in saline as measured by MTT analysis. However, exposing human mucosal cells to ethanol in combination with TOB leads to increased cell survival. Additionally, exposing mucosal cells to the lethal combination of nicotine and ethanol leads to $49 \%$ survival after $2 \mathrm{~h}$, but when TOB is added, $94 \%$ survival takes place.

A common feature in the progression toward cell death is mitochondrial dysfunction that is associated with the release of cytochrome $c$ from the mitochondria into the cytoplasm [34-40]. The presence of cytochrome $c$ in the cytoplasm is often detected after a broad range of insults during acute and chronic cellular injury [37, 38, 40-42]. Once in the cytosol, cytochrome $c$ associates with Apaf-1 to form the 'apoptosome' in conjunction with procaspase-9 which undergoes autocatalytic proteolysis to mature caspase-9. In turn, caspase-9 activates caspase-3, which in turn plays an important role in cell death [43, 44].

The toxicity induced by the ethanol + nicotine combination correlates with a dramatic increase in caspase-3 and -9 activity and release of cytochrome $c$ into the cytosol. The addition of tincture benzoin, however, reduces caspase- 3 and -9 activity and also inhibits release of cytochrome $c$ into the cytosol. It is possible that the addition of TOB stabilizes the mucosal cell membranes, thereby preventing the ethanol + nicotine-induced release of cytochrome $c$ into the cytosol and subsequent triggering of caspase- 3 and -9 . The levels of caspase- 3 and -9 activity observed with the cytoprotection conferred by TOB are equivalent to the activity noted when the cells are pre-treated with the caspase inhibitor z-VAD-FMK. The cause and effect relationship between caspase- 3 and 9 activation and apoptosis was demonstrated by the use of z-VAD-FMK. This inhibitor suppressed ethanol-mediated caspase-3 and -9 activation and attenuated ethanol-induced apoptosis, similar to that noted in hepatic cells exposed to ethanol [45]. As far as we know, this is the first study to demonstrate that ethanol + nicotine induces human mucosal cell apoptosis through activation of caspase-3 and -9 secondary to release of cytochrome $c$ into the cytosol. The significant apoptosis observed in this study correlates with the toxic synergy of tobacco smoking and alcohol consumption which leads to a 40-fold increase in head and neck cancers compared with the risk of smoking or drinking alcohol alone. Given that the combination of TOB with nicotine leads to a rapid but prolonged delivery of nicotine along with a significant cytoprotective effect, further pharmacokinetic studies of this potentially beneficial transmucosal NRT product are warranted.

\section{Compliance with Ethical Standards}

Conflict of interest Drs Alex Battaglia and Thanh Nguyen independently performed this study while employed by Jaleva Pharmaceuticals, which has subsequently been acquired by Advanced Resin Therapeutics. Dr Battaglia is currently a board member and equity owner of Advanced Resin Therapeutics, Inc., which owns the intellectual property associated with the TOB technology described in this paper.

\section{Sponsorship None.}

\section{Funding Source None.}

Open Access This article is distributed under the terms of the Creative Commons Attribution-NonCommercial 4.0 International License (http://creativecommons.org/licenses/by-nc/4.0/), which permits any noncommercial use, distribution, and reproduction in any medium, provided you give appropriate credit to the original author(s) and the source, provide a link to the Creative Commons license, and indicate if changes were made.

\section{References}

1. Harrell PT, Simmons VN, Correa JB, Padhya TA, Brandon TH. Electronic nicotine delivery systems ("e-cigarettes"): review of safety and smoking cessation efficacy. Otolaryngol Head Neck Surg. 2014;151(3):381-93.

2. Hughes JR, Shiffman S, Callas P, Zhang J. A meta-analysis of the efficacy of over-the-counter nicotine replacement. Tob Control. 2003;12:21-7.

3. Shiffman S, Shadel WG, Niaura R, Khayrallah MA, Jorenby DE, Ryan CF, Ferguson CL. Efficacy of acute administration of nicotine gum in relief of cue-provoked cigarette craving. Psychopharmacology (Berl). 2003;166(4):343-50.

4. Shiffman S, Paty JA, Gnys M, Kassel JA, Hickcox M. First lapses to smoking: within subjects analysis of real-time reports. J Consult Clin Psychol. 1996;64:366-79.

5. Pellegrino RM, Tinghino B, Mangiaracina G, Marani A, Vitali M, Protano C, Osborn JF, Cattaruzza MS. Electronic cigarettes: an evaluation of exposure to chemicals and fine particulate matter (PM). Ann Ig. 2012;24(4):279-88.

6. Ingebrethsen BJ, Cole SK, Alderman SL. Electronic cigarette aerosol particle size distribution measurements. Inhal Toxicol. 2012;24(14):976-84.

7. Schripp T, Markewitz D, Uhde E, Salthammer T. Does e-cigarette consumption cause passive vaping? Indoor Air. 2013;23(1):25-31.

8. Zhang Y, Sumner W, Chen DR. In vitro particle size distributions in electronic and conventional cigarette aerosols suggest comparable deposition patterns. Nicotine Tob Res. 2013;15(2):501-8.

9. Vardavas CI, Anagnostopoulos N, Kougias M, Evangelopoulou V, Connolly GN, Behrakis PK. Short-term pulmonary effects of using an electronic cigarette: impact on respiratory flow resistance, impedance, and exhaled nitric oxide. Chest. 2012;141(6):1400-6.

10. Adkison SE, O'Connor RJ, Bansal-Travers M, Hyland A, Borland R, Yong HH, Cummings KM, McNeill A, Thrasher JF, Hammond D, Fong GT. Electronic nicotine delivery systems: international tobacco control four-country survey. Am J Prev Med. 2013;44(3):207-15. 
11. Popova L, Ling PM. Alternative tobacco product use and smoking cessation: a national study. Am J Public Health. 2013;103(5):923-30.

12. Vickerman KA, Carpenter KM, Altman T, Nash CM, Zbikowski SM. Use of electronic eigarettes among state tobacco cessation quitline callers. Nicotine Tob Res. 2013;15(10):1787-91.

13. Durrheim H, Flynn GL, Higuchi WI, Behl CR. Permeation of hairless mouse skin. 1. Experimental methods and comparison with human epidermal permeation by alkanols. J Pharm Sci. 1980;69:781-6.

14. Friend D, Catz P, Heller J, Reid J, Baker R. Transdermal delivery of levonorgestrel. 1. Alkanols as permeation enhancers in vitro. J Control Release. 1988;7:243-50.

15. Berner B, Mazzenga GC, Otte JH, Steffens RJ, Juang RH, Ebert CD. Ethanol: water mutually enhanced transdermal therapeutic system II: skin permeation of ethanol and nitroglycerin. J Pharm Sci. 1989;78:402-7.

16. Pershing LK, Lambert LD, Knutson K. Mechanism of ethanolenhanced estradiol permeation across human skin in vivo. Pharm Res. 1990;7:170-5.

17. Kurihara-Bergstrom T, Knutson K, DeNoble LJ, Goates CY. Percutaneous-absorption enhancement of an ionic molecule by ethanol water-systems in human skin. Pharm Res. 1990;7:762-6.

18. Okabe H, Takayama K, Nagai T. Percutaneous absorption of ketoprofen from acrylic gel patches containing d-limonene and ethanol as absorption enhancers. Chem Pharm Bull (Tokyo). 1992;40:1906-10.

19. Megrab NA, Williams AC, Barry BW. Oestradiol permeation across human skin, silastic and snake skin membranes: the effects of ethanol-water cosolvent systems. Int $\mathrm{J}$ Pharm. 1995;116:101-12.

20. Goldberg-Cettina M, Liu P, Nightingale J, Kurihara-Bergstrom T. Enhanced transdermal delivery of estradiol in-vitro using binary vehicles of isopropyl myristate and short-chain alkanols. Int $\mathbf{J}$ Pharm. 1995;114:237-45.

21. Kim DD, Kim JL, Chien YW. Mutual hairless rat skin permeation-enhancing effect of ethanol/water system and oleic acid. J Pharm Sci. 1996;85:1191-5.

22. Stinecipher J, Shah J. Percutaneous permeation of $N, N$-diethyl-mtoluamide (DEET) from commercial mosquito repellents and the effect of solvent. J Toxicol Environ Health. 1997;52:119-35.

23. Walters KA, Brain KR, Dressler WE, Green DM, Howes D, James VJ, Kelling CK, Watkinson AC, Gettings SD. Percutaneous penetration of $N$-nitroso- $N$-methyldodecylamine through human skin in vitro: application from cosmetic vehicles. Food Chem Toxicol. 1997;35:705-12.

24. Sloan KB, Beall HD, Taylor HE, Getz JJ, Villaneuva R, Nipper $\mathrm{R}$, Smith K. Transdermal delivery of theophylline from alcohol vehicles. Int J Pharm. 1998;171:185-93.

25. Levang AK, Zhao K, Singh J. Effect of ethanol/propylene glycol on the in vitro percutaneous absorption of aspirin, biophysical changes and macroscopic barrier properties of the skin. Int $\mathbf{J}$ Pharm. 1999;181:255-63.

26. Panchagnula R, Salve PS, Thomas NS, Jain AK, Ramarao P. Transdermal delivery of naloxone: effect of water, propylene glycol, ethanol and their binary combinations on permeation through rat skin. Int J Pharm. 2001;219:95-105.

27. Heard CM, Kung D, Thomas CP. Skin penetration enhancement of mefenamic acid by ethanol and 1,8-cineole can be explained by the 'pull' effect. Int J Pharm. 2006;321:167-70.

28. Heard CM, Screen C. Probing the permeation enhancement of mefenamic acid by ethanol across full-thickness skin, heat- separated epidermal membrane and heat-separated dermal membrane. Int J Pharm. 2008;349:323-5.

29. Meyer F, Ziegenmeyer J. The absorption potential of skin. J Soc Cosmet Chem. 1975;26:93-104.

30. Bommanan D, Potts R, Guy RH. Examination of the effect of ethanol on human stratum-corneum invivo using infrared-spectroscopy. J Control Release. 1991;16:299-304.

31. Kai T, Mak VHW, Potts RO, Guy RH. Mechanism of percutaneous penetration enhancement: effect of $n$-alkanols on the permeability barrier of hairless mouse skin. J Control Release. 1990;12:103-12.

32. Van der Merwe D, Riviere JE. Comparative studies on the effects of water, ethanol and water/ethanol mixtures on chemical partitioning into porcine stratum corneum and silastic membrane. Toxicol In Vitro. 2005;19:69-77.

33. Goates CY, Knutson K. Enhanced permeation of polar compounds through human epidermis. I. Permeability and membrane structural changes in the presence of short chain alcohols. Biochim Biophys Acta. 1994;1195:169-79.

34. Beal MF. Mitochondria NO and neurodegeneration. Biochem Soc. 1999;66:43-54.

35. Bernardi P, Scorrano L, Colonna R, Petronilli V, Di Lisa F. Mitochondria and cell death. Mechanistic aspects and methodological issues. Eur J Biochem. 1999;264:687-701.

36. Chan PH. Mitochondria and neuronal death/survival signaling pathways in cerebral ischemia. Neurochem Res. 2004;29:1943-9.

37. Friedlander RM. Apoptosis and caspases in neurodegenerative diseases. N Engl J Med. 2003;348:1365-75.

38. Wang X, Zhu S, Drozda M, Zhang W, Stavrovskaya IG, Cattaneo E, Ferrante RJ, Kristal BS, Friedlander RM. Minocycline inhibits caspase-independent and-dependent mitochondrial cell death pathways in models of Huntington's disease. Proc Natl Acad Sci USA. 2003;100:10483-7.

39. Zhang WH, Wang X, Narayanan M, Zhang Y, Huo C, Reed JC, Friedlander RM. Fundamental role of the Rip2/caspase-1 pathway in hypoxia and ischemia-induced neuronal cell death. Proc Natl Acad Sci USA. 2003;100:16012-7.

40. Zhu S, Stavrovskaya IG, Drozda M, Kim BY, Ona V, Li M, Sarang S, Liu AS, Hartley DM, Wu DC, Gullans S, Ferrante RJ, Przedborski S, Kristal BS, Friedlander RM. Minocycline inhibits cytochrome $c$ release and delays progression of amyotrophic lateral sclerosis in mice. Nature. 2002;417:74-8.

41. Hengartner MO. The biochemistry of apoptosis. Nature. 2000;407:770-6.

42. Rigamonti D, Sipione S, Goffredo D, Zuccato C, Fossale E, Cattaneo E. Huntingtin's neuroprotective activity occurs via inhibition of procaspase-9 processing. J Biol Chem. 2001;276:14545-8.

43. Li P, Nijhawan D, Budihardjo I, Srinivasula SM, Ahmad M, Alnemri ES, Wang X. Cytochrome $c$ and dATP-dependent formation of Apaf-1/caspase-9 complex initiates an apoptotic protease cascade. Cell. 1997;91:479-89.

44. Zou H, Henzel WJ, Liu X, Lutschg A, Wang X. Apaf-1, a human protein homologous to $C$. elegans CED-4, participates in cytochrome $c$-dependent activation of caspase-3. Cell. 1997;90:405-13.

45. Roychowdhury S, Chiang DJ, Mandal P, McMullen MR, Liu X, Cohen JI, Pollard J, Feldstein AE, Nagy LE. Inhibition of apoptosis protects mice from ethanol-mediated acceleration of early markers of $\mathrm{CCl} 4$-induced fibrosis but not steatosis or inflammation. Alcohol Clin Exp Res. 2012;36(7):1139-47. 